Texte Metzler 16

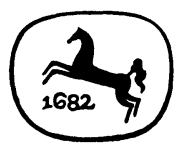


Marie Luise Gansberg

Paul Gerhard Völker

\section{Methodenkritik der Germanistik}

Materialistische Literaturtheorie

und bürgerliche Praxis

2., unveränderte Auflage (4.-6. Tsd.)

J. B. Metzlersche Verlagsbuchhandlung Stuttgart 1971 
ISBN 978-3-476-00045-3

ISBN 978-3-476-02972-0 (eBook)

DOI 10.1007/978-3-476-02972-0

(C) 1970 Springer-Verlag GmbH Deutschland

Ursprünglich erschienen bei J. B. Metzlersche Verlagsbuchhandlung und Carl Ernst Poeschel Verlag GmbH in Stuttgart 1970 


\section{INHALT}

Marie Luise Gansberg

$\mathrm{Zu}$ einigen populären Vorurteilen gegen materialistische Literaturwissenschaft

Paul Gerhard Völker

Die inhumane Praxis einer bürgerlichen Wissenschaft

Paul Gerhard Völker

Skizze einer marxistischen Literaturwissenschaft

Anmerkungen 